\title{
A POSTURA CORPORAL E AS FUNÇÕES ESTOMATOGNÁTICAS EM CRIANÇAS RESPIRADORAS ORAIS: UMA REVISÃO DE LITERATURA
}

\author{
Body posture and the stomatognathic functions \\ in mouth breathing children: a literature review
}

Patricia Girarde Machado ${ }^{(1)}$, Carolina Lisbôa Mezzomo ${ }^{(2)}$, Ana Fátima Viero Badaró (3)

\begin{abstract}
RESUMO
A postura corporal das crianças é objeto de crescente estudo na fisioterapia, assim como as crianças respiradoras orais o são na fonoaudiologia. Este estudo tem por objetivo verificar, na literatura científica, as funções estomatognáticas, a postura corporal e suas relações, em crianças respiradoras orais. Trata-se de uma revisão da literatura sobre a postura corporal, e o sistema estomatognático e suas relações em respiradores orais obstrutivos e funcionais. Buscou-se nas bases de dados eletrônicos MEDLINE, SCIELO e LILACS, e Googlecientífico, artigos que relacionassem esses temas nos últimos 10 anos. Os artigos selecionados foram organizados de acordo com os autores, o título, a origem, a faixa etária e o ano de publicação. Após a seleção dos textos, foram identificados apenas quatro trabalhos que relacionam postura, sistema estomatognático e respiração oral; dois que relacionam sistema estomatognático e postura; e a maioria, treze que estudam sistema estomatognático e respiração oral; dentre outros. Notou-se que há uma escassez de informações sobre a relação da postura corporal com o sistema estomatognático em respiradores orais. A escassez é ainda maior quando se compara o grupo de respiradores orais obstrutivos e respiradores orais funcionais relacionando a postura corporal com o sistema estomatognático.
\end{abstract}

DESCRITORES: Postura; Sistema Estomatognático; Respiração Bucal; Criança

\section{INTRODUÇÃO}

O Sistema Estomatognático (SE) é formado por um conjunto complexo de estruturas que podem ser divididas em estáticas, passivas e dinâmicas ou ativas. As primeiras são constituídas pelos arcos dentários, maxila e mandíbula, relacionadas entre si

(1) Fisioterapeuta; Mestranda do Curso de Pós-graduação em Distúrbios da Comunicação Humana da Universidade Federal de Santa Maria, UFSM, Santa Maria, RS, Brasil; Especialista em Atividade Física, Desempenho Motor e Saúde.

(2) Fonoaudióloga; Professora Adjunta da Universidade Federal de Santa Maria, UFSM, Santa Maria, RS, Brasil; Doutora em Linguística e Letras pela Pontifícia Universidade Católica do Rio Grande do Sul, Brasil.

(3) Fisioterapeuta; Professora Adjunta da Universidade Federal de Santa Maria, UFSM, Santa Maria, RS, Brasil; Doutora em Ciências da Saúde pela Universidade de Brasília, Brasil.

Conflito de interesses: inexistente pela articulação temporomandibular (ATM). Fazem parte destas estruturas o osso hióide e outros ossos cranianos. Já as dinâmicas ou ativas são representadas pela unidade neuromuscular, que mobiliza as partes estáticas. Essas estruturas se interligam para a realização das funções vitais do organismo (respiração, sucção, mastigação, deglutição) e sociais (fonação e articulação), que são de extrema importância para a manutenção de todo o equilíbrio físico-biológico do ser humano. Elas formam um sistema de características próprias, localizadas na cavidade oral, e não são especializadas em uma só função. Portanto, alterações em qualquer de suas partes levam a um desequilíbrio geral desse sistema ${ }^{1,2}$.

Durante alguns anos o trabalho fonoaudiológico relacionado ao sistema estomatognático se restringiu, basicamente, à função de deglutição. Porém, atualmente, vários autores têm mostrado a importância de outras funções, como a mastigação 
e a respiração, para o desenvolvimento e o crescimento desse sistema ${ }^{3}$. Além disso, outros profissionais, como fisioterapeutas, odontólogos, otorrinolaringologistas e oftalmologistas, têm se associado para ampliar esses estudos.

Desde o nascimento, a respiração nasal é uma situação vital para o ser humano. Essa é a respiração fisiológica, a qual favorece o crescimento e um bom desenvolvimento anatômico e funcional das mais diversas estruturas do corpo. Influencia diretamente a manutenção da organização esquelética, dentária e muscular do sistema estomatognático, das funções orofaciais, além do desenvolvimento físico e intelectual ${ }^{4-6}$.

Interrompendo o processo fisiológico da respiração, tem-se a respiração oral (RO), uma adaptação funcional que acarreta modificações não somente nos órgãos e aparelhos diretamente envolvidos, mas também na dinâmica corporal como um todo ${ }^{4,5,7}$. A RO é uma função adaptativa do sistema estomatognático que pode promover alterações estruturais que permitem sua instalação e funcionalidade. Quando isso acontece, compromete o equilíbrio existente entre as funções mastigatórias, de deglutição, respiração e fonação, condição necessária para o bom desenvolvimento e normal crescimento desse sistema ${ }^{8}$.

Por essa razão, favorece o aparecimento de alterações posturais, pois a criança que respira cronicamente pela boca, para conseguir respirar melhor, necessita adaptar a postura da cabeça, anteriorizando-a para que o ar chegue mais rapidamente aos pulmões, ou seja, flexiona o pescoço para frente, retificando o trajeto das vias respiratórias ${ }^{9}$. A anteriorização da cabeça provoca alterações da postura da mandíbula, do osso hióide e da língua, trazendo consequências para o crescimento ósseo facial e para a oclusão e interferindo na competência das funções alimentares (sucção, mastigação e deglutição), o que se deve à conformação anatômica em cadeia dos elementos ósteo-musculares dessa região ${ }^{1,2}$.

No intuito de compensar este mau posicionamento da cabeça em relação ao pescoço, a coluna e o restante do corpo sofrem alterações. Ao flexionar o pescoço para frente, as escápulas se elevam e a região anterior do tórax fica deprimida, tornando a respiração mais rápida e curta, com pequena ação do diafragma. $O$ relaxamento deste músculo e do músculo reto-abdominal, associado a uma ingestão de ar constante, leva a criança respiradora oral a projetar o abdômen. Essas alterações musculares fazem com que o corpo tenda a ir para frente e para baixo, provocando novas compensações na postura de braços e pernas, que por sua vez assumem um alinhamento corporal fora dos padrões anatômicos ideais para compensar os desequilíbrios causados pelas alterações respiratórias ${ }^{10}$. Essas alterações podem levar a descompensações pulmonares, cardíacas, viscerais, físicas, comportamentais, entre outras ${ }^{1}$.

Atualmente, muitos estudos sobre a RO têm sido desenvolvidos, discutindo suas características e todas as alterações que este padrão respiratório acarreta. Também muitos profissionais são solicitados para tratar dessa patologia, já que as suas consequências podem ser as mais variadas possíveis. Diante do exposto, o presente estudo apresenta uma revisão da literatura nos últimos 10 anos sobre a temática que envolve as funções estomatognáticas e a postura corporal de crianças respiradoras orais obstrutivas e funcionais.

\section{MÉTODO}

Este é um estudo exploratório em que se utiliza a técnica de revisão não-sistemática da literatura, com a qual se buscou construir um referencial teórico sobre a postura corporal e o sistema estomatognático em respiradores orais obstrutivos e funcionais. A fim de se atingir o objetivo do estudo, foi realizada uma pesquisa de artigos em diferentes bases de dados eletrônicos, a saber MedLine/ PubMed, SciELO, LILACS e Googlecientífico.

Os artigos foram incluídos de acordo com os seguintes critérios: data de publicação e abordagem de temas relacionados às questões de postura corporal, funções estomatognáticas e/ou respiração oral em crianças. Utilizou-se para a busca dos artigos os seguintes termos: Respirador Bucal/ Oral; Respirador Bucal/Oral Obstrutivo; Respirador Bucal/Oral Funcional; e Sistema Estomatognático e Postura. Também foram feitas buscas pelas associações: sistema estomatognático e postura; sistema estomatognático e respiração bucal/oral; respiração bucal/oral e postura. Foram excluídos os artigos que tratavam do tema relacionado a adultos.

Os temas foram pesquisados nos títulos e/ou nos resumos dos estudos examinados de acordo com os critérios de inclusão e exclusão.

Os artigos selecionados foram organizados de acordo com os autores, o título, a origem, a faixa etária e o ano de publicação. A classificação dos periódicos foi realizada conforme o tipo do estudo e a temática envolvida. Quanto ao tipo, os estudos foram considerados: artigo de revisão de literatura; análise descritiva dos dados; pesquisa de campo; estudo observacional; estudo de caso e estudo piloto.

Para a classificação da temática, utilizou-se as seguintes associações: sistema estomatognático e postura (SE/PO); sistema estomatognático e 
respiração oral (SE/RO); respiração oral e postura (RO/PO); respirador oral obstrutivo e respirador oral funcional (ROO/ROF); sistema estomatognático, postura e respirador oral (SE/PO/RO), sendo os resultados obtidos para estas associações apresentados por frequência simples. Após, as informações derivadas da literatura foram delineadas considerando as temáticas mais gerais, a saber: 1. Sistema Estomatognático e a respiração oral; 2. Relação da postura corporal com as funções estomatognáticas; e 3. Relação da postura corporal com as funções estomatognáticas nos respiradores orais.

Após a seleção dos textos, identificaram-se as seguintes relações temáticas:

- Sistema estomatognático e respiração oral (SE/ RO) (14);

- Sistema estomatognático e postura - (SE/PO) (3);

- Sistema estomatognático, respiração oral e postura (SE/RO/PO) (5);

- Sistema estomatognático, respiração oral (obstrutivo e funcional) e postura (SE/ROO/ ROF/PO) (1);

- Respiração oral e postura (RO/PO) (8);

- Postura e respirador oral - obstrutivo e funcional - (1);

- Sistema estomatognático e respirador oral obstrutivo e funcional (1);

- Respiração oral (6);

- Fala e respirador oral (1).

Tais associações foram utilizadas apenas para busca e posterior classificação dos estudos, a fim de torná-lo mais didático. Conforme foram sendo realizadas as buscas, as associações previstas na metodologia não atenderam aos resultados encontrados, portanto optou-se por ampliar as combinações previamente estabelecidas.

Segue-se a descrição dos resultados da apresentação dos textos, seguindo o método citado anteriormente. Conforme busca: 1. Sistema Estomatognático e a respiração oral; 2. Relação da postura corporal com as funções estomatognáticas; e 3. Relação da postura corporal com as funções estomatognáticas nos respiradores orais.

\section{REVISÃO DA LITERATURA}

A partir da busca realizada, seguindo os critérios pré-estabelecidos, foi encontrado um total de 40 artigos. A Figura 1 mostra o número de artigos encontrados na busca, organizados de acordo com os autores, o título, a origem, a faixa etária e o ano de publicação. Ainda, apresentam a classificação dos periódicos conforme o tipo do estudo e a classificação da temática.

Conforme apontada na Figura 1, ao classificar os artigos quanto ao tipo, observou-se que 5 apresentam análise descritiva dos dados; 21 referem-se à pesquisa de campo; 1 diz respeito à estudo observacional; 1 à estudo de caso e 1 à estudos piloto. De forma geral, observa-se uma predominância de estudos nacionais na literatura consultada. Quanto à classificação da temática, observou-se que há um maior número de estudos sobre sistema estomatognático. Observa-se, assim, um predomínio de artigos que relacionam sistema estomatognático e respiração oral (13) e a escassez de artigos que trazem informações sobre sistema estomatognático e respirador oral obstrutivo e funcional. Assim como uma escassez entre a relação que há de postura e respiração oral obstrutiva e funcional.

Após a apresentação das informações sobre os tipos e classificação dos artigos encontrados, seguem informações derivadas da literatura revisada, delineadas a partir das temáticas: sistema estomatognático e a respiração oral; relação da postura corporal com as funções estomatognáticas; e relação da postura corporal com as funções estomatognáticas nos respiradores orais. 


\begin{tabular}{|c|c|c|c|c|c|c|c|}
\hline \multirow[b]{2}{*}{$\mathbf{N}^{\circ}$} & \multirow[b]{2}{*}{ Autor (es) } & \multirow[b]{2}{*}{ Título } & \multirow[b]{2}{*}{ Origem } & \multirow{2}{*}{$\begin{array}{l}\text { Faixa } \\
\text { Etária }\end{array}$} & \multicolumn{2}{|c|}{ Classificação } & \multirow[b]{2}{*}{ Ano } \\
\hline & & & & & $\begin{array}{l}\text { Tipo de } \\
\text { Estudo }\end{array}$ & Temática & \\
\hline I & $\begin{array}{l}\text { Godoy P, Niitsuma } \\
\text { LEM; Caromano } \\
\text { FA, }\end{array}$ & $\begin{array}{l}\text { Avaliação Funcional } \\
\text { Fisioterapêutica do } \\
\text { Respirador Bucal. }\end{array}$ & Nacional & Criança & $\begin{array}{l}\text { Artigo } \\
\text { revisão }\end{array}$ & $\begin{array}{l}\text { RO } \\
\text { PO }\end{array}$ & 2000 \\
\hline II & $\begin{array}{l}\text { Krakauer LH; } \\
\text { Guilherme A }\end{array}$ & $\begin{array}{l}\text { The Relantionship between } \\
\text { Mouth Breathing and Postural } \\
\text { Alterations in Children: a } \\
\text { descriptive analysis. }\end{array}$ & Nacional & $\begin{array}{l}5-10 \\
\text { anos }\end{array}$ & $\begin{array}{l}\text { Análise } \\
\text { descritiva }\end{array}$ & $\begin{array}{l}\mathrm{RO} / \mathrm{RN} \\
\mathrm{PO}\end{array}$ & 2000 \\
\hline III & $\begin{array}{l}\text { Motonaga SM; } \\
\text { Berte LC; } \\
\text { Anselmo-Lima } \\
\text { WT. }\end{array}$ & $\begin{array}{l}\text { Respiração Bucal: causas e } \\
\text { alterações no sistema } \\
\text { estomatognático. }\end{array}$ & Nacional & $\begin{array}{l}3-10 \\
\text { anos }\end{array}$ & $\begin{array}{l}\text { Pesquisa } \\
\text { de } \\
\text { campo }\end{array}$ & $\begin{array}{l}\text { RO } \\
\text { SE }\end{array}$ & 2000 \\
\hline IV & Oliveira TC & $\begin{array}{l}\text { Síndrome do Respirador } \\
\text { Bucal: análise fisiopatológica } \\
\text { e uma abordagem } \\
\text { fisioterapêutica } \\
\text { neumofuncional. }\end{array}$ & Nacional & Criança & $\begin{array}{l}\text { Artigo } \\
\text { revisão }\end{array}$ & $\begin{array}{l}\text { RO } \\
\text { PO } \\
\text { SE }\end{array}$ & 2001 \\
\hline $\mathbf{V}$ & Arellano, J.C.V. & $\begin{array}{l}\text { Relações entre Postura } \\
\text { Corporal e Sistema } \\
\text { Estomatognático. }\end{array}$ & Nacional & Criança & $\begin{array}{l}\text { Artigo } \\
\text { revisão }\end{array}$ & $\begin{array}{l}\text { SE } \\
\text { PO }\end{array}$ & 2002 \\
\hline VI & $\begin{array}{l}\text { Falcão DA; } \\
\text { Grinfeld S; } \\
\text { Grinfeld A; Melo } \\
\text { MVR. }\end{array}$ & $\begin{array}{l}\text { Oral Breathers Clinically } \\
\text { Diagnosed and by } \\
\text { Autodiagnosed. Body Posture } \\
\text { Consequences. }\end{array}$ & Intern & $\begin{array}{l}8-16 \\
\text { anos }\end{array}$ & $\begin{array}{l}\text { Pesquisa } \\
\text { de } \\
\text { campo }\end{array}$ & $\begin{array}{l}\text { RON/RNO } \\
\text { SE } \\
\text { PO }\end{array}$ & 2003 \\
\hline VII & $\begin{array}{l}\text { Coelho MF, Terra } \\
\text { VHTC }\end{array}$ & $\begin{array}{l}\text { Implicações Clínicas em } \\
\text { Pacientes Respiradores } \\
\text { Bucais. }\end{array}$ & Nacional & Criança & $\begin{array}{l}\text { Artigo } \\
\text { revisão }\end{array}$ & $\begin{array}{l}\text { RO } \\
\text { SE }\end{array}$ & 2004 \\
\hline VIII & Parra & $\begin{array}{l}\text { El Paciente Respirador Bucal } \\
\text { una Propuesta para el Estado } \\
\text { Nueva Esparta }\end{array}$ & $\begin{array}{c}\text { Internacio } \\
\text { nal }\end{array}$ & $\begin{array}{l}5-14 \\
\text { anos }\end{array}$ & $\begin{array}{l}\text { Pesquisa } \\
\text { de } \\
\text { campo }\end{array}$ & $\begin{array}{l}\text { RO } \\
\text { SE }\end{array}$ & 2004 \\
\hline IX & $\begin{array}{l}\text { Quintão Fc; } \\
\text { Andrade DC; } \\
\text { Lagôa LC }\end{array}$ & $\begin{array}{l}\text { A Síndrome do Respirador } \\
\text { Oral, suas Influências na } \\
\text { Postura e a Atuação da } \\
\text { Fisioterapia. }\end{array}$ & Nacional & Criança & $\begin{array}{l}\text { Artigo } \\
\text { Revisão }\end{array}$ & $\begin{array}{l}\text { RO } \\
\text { PO }\end{array}$ & 2004 \\
\hline$x$ & Lima LCO et al. & $\begin{array}{l}\text { Postural Alterations in } \\
\text { Children with Mouth Breathing } \\
\text { Assessed by Computerized } \\
\text { Biophotogrammetry. }\end{array}$ & Intern & $\begin{array}{l}8-10 \\
\text { anos }\end{array}$ & $\begin{array}{l}\text { Pesquisa } \\
\text { de } \\
\text { campo }\end{array}$ & $\begin{array}{l}\text { ROO/ROF } \\
\text { RN } \\
\text { PO }\end{array}$ & 2004 \\
\hline $\mathbf{X I}$ & $\begin{array}{l}\text { Di Francesco RC; } \\
\text { Passerotii G; } \\
\text { Paulucci B; Miniti } \\
\text { A }\end{array}$ & $\begin{array}{l}\text { Respiração Oral na Criança: } \\
\text { repercussões diferentes de } \\
\text { acordo com o diagnóstico. }\end{array}$ & Nacional & $\begin{array}{l}2-16 \\
\text { anos }\end{array}$ & $\begin{array}{l}\text { Pesquisa } \\
\text { de } \\
\text { campo }\end{array}$ & $\begin{array}{l}\text { ROO/ROF } \\
\text { SE }\end{array}$ & 2004 \\
\hline XII & $\begin{array}{l}\text { Silva APPP; } \\
\text { Vitalino RAB; } \\
\text { Martinez M; } \\
\text { Chiappetta ALML. }\end{array}$ & $\begin{array}{l}\text { Correlação entre Postura } \\
\text { Corporal e Mastigação Após a } \\
\text { Dentição Mista. }\end{array}$ & Nacional & & Relação & $\begin{array}{l}\text { SE } \\
\mathrm{PO}\end{array}$ & 2004 \\
\hline XIII & $\begin{array}{l}\text { Costa JR; Pereira } \\
\text { SRA; Mitri G; } \\
\text { Motta JC; } \\
\text { Pignatari SSN; } \\
\text { Weckx LLM. }\end{array}$ & $\begin{array}{l}\text { Relação da Oclusão Dentária } \\
\text { com a Postura de Cabeça e } \\
\text { Coluna Cervical em Crianças } \\
\text { Respiradoras Orais. }\end{array}$ & Nacional & $\begin{array}{l}5-12 \\
\text { anos }\end{array}$ & $\begin{array}{l}\text { Pesquisa } \\
\text { de } \\
\text { campo }\end{array}$ & $\begin{array}{l}\text { RO } \\
\text { SE } \\
\text { PO }\end{array}$ & 2005 \\
\hline XIV & $\begin{array}{l}\text { Val DC Do; } \\
\text { Limongi SCO; } \\
\text { Flabiano FC; Silva } \\
\text { KCL. }\end{array}$ & $\begin{array}{l}\text { Stomatognathic System and } \\
\text { Body Posture in Children with } \\
\text { Sensoriomotor Deficits. }\end{array}$ & Nacional & $1-6$ anos & $\begin{array}{l}\text { Pesquisa } \\
\text { de } \\
\text { campo }\end{array}$ & $\begin{array}{l}\text { SE } \\
\text { PO }\end{array}$ & 2005 \\
\hline $\mathbf{X V}$ & $\begin{array}{l}\text { Rodrigues HOSN; } \\
\text { Faria SR; Paula } \\
\text { FSG; Motta AR }\end{array}$ & $\begin{array}{l}\text { Ocorrência de Respiração } \\
\text { Oral e Alterações } \\
\text { Miofuncionais Orofaciais em } \\
\text { Sujeitos em Tratamento } \\
\text { Ortodôntico }\end{array}$ & Nacional & $\begin{array}{l}7-36 \\
\text { anos }\end{array}$ & $\begin{array}{l}\text { Pesquisa } \\
\text { de } \\
\text { campo }\end{array}$ & RO & 2005 \\
\hline $\mathbf{X V I}$ & $\begin{array}{l}\text { Bicalho GP; Motta } \\
\text { AR; Vicente LCC }\end{array}$ & $\begin{array}{l}\text { Evaluation of Swallowing in } \\
\text { Mouth Breathing Children }\end{array}$ & Nacional & $\begin{array}{l}4-11 \\
\text { anos }\end{array}$ & $\begin{array}{l}\text { Análise } \\
\text { descritiva }\end{array}$ & $\begin{array}{l}\text { RO } \\
\text { SE }\end{array}$ & 2006 \\
\hline XVII & $\begin{array}{l}\text { Silveira MC; } \\
\text { Sígolo C; Quintal } \\
\text { M;Sakano E; } \\
\text { Tessitore A. }\end{array}$ & $\begin{array}{l}\text { Proposta de Documentação } \\
\text { Fotográfica em Motricidade } \\
\text { Oral. }\end{array}$ & Nacional & $\begin{array}{l}5-15 \\
\text { anos }\end{array}$ & $\begin{array}{l}\text { Pesquisa } \\
\text { de } \\
\text { campo }\end{array}$ & RO & 2006 \\
\hline
\end{tabular}




\begin{tabular}{|c|c|c|c|c|c|c|c|}
\hline \multirow[b]{2}{*}{$\mathbf{N}^{\circ}$} & \multirow[b]{2}{*}{ Autor (es) } & \multirow[b]{2}{*}{ Título } & \multirow[b]{2}{*}{ Origem } & \multirow{2}{*}{$\begin{array}{l}\text { Faixa } \\
\text { Etária }\end{array}$} & \multicolumn{2}{|c|}{ Classificação } & \multirow[b]{2}{*}{ Ano } \\
\hline & & & & & $\begin{array}{l}\text { Tipo de } \\
\text { Estudo }\end{array}$ & Temática & \\
\hline XVIII & $\begin{array}{l}\text { Filho DI; Bertolini } \\
\text { MM; Lopes ML }\end{array}$ & $\begin{array}{l}\text { Contribuição Multidisciplinar } \\
\text { no Diagnóstico e no } \\
\text { Tratamento das Obstruções } \\
\text { da Nasofaringe e da } \\
\text { Respiração Bucal. }\end{array}$ & Nacional & Criança & $\begin{array}{l}\text { Artigo } \\
\text { revisão }\end{array}$ & $\begin{array}{l}\text { RO } \\
\text { SE }\end{array}$ & 2006 \\
\hline${ }^{*} \mathbf{X I X}$ & $\begin{array}{l}\text { Barros JRC; } \\
\text { Becker HMG; } \\
\text { Pinto JA. }\end{array}$ & $\begin{array}{l}\text { Evaluation of Atopy Among } \\
\text { Mouth-Breathing Pediatric } \\
\text { Patients Referred for } \\
\text { Treatment to a Tertiary Care } \\
\text { Center. }\end{array}$ & Intern & $\begin{array}{l}2-12 \\
\text { anos }\end{array}$ & $\begin{array}{l}\text { Análise } \\
\text { descritiva }\end{array}$ & $\begin{array}{l}\text { RO } \\
\text { SE }\end{array}$ & 2006 \\
\hline $\mathbf{X X}$ & $\begin{array}{l}\text { Lemos CM; } \\
\text { Junqueira PAS; } \\
\text { Gomez MVSG; } \\
\text { Faria MEJ; Basso } \\
\text { SC }\end{array}$ & $\begin{array}{l}\text { Estudo da Relação entre a } \\
\text { Oclusão Dentária e a } \\
\text { Deglutição no Respirador } \\
\text { Oral. }\end{array}$ & Nacional & $\begin{array}{l}5-12 \\
\text { anos }\end{array}$ & $\begin{array}{l}\text { Pesquisa } \\
\text { de } \\
\text { campo }\end{array}$ & $\begin{array}{l}\text { RO } \\
\text { SE }\end{array}$ & 2006 \\
\hline $\mathbf{X X I}$ & $\begin{array}{l}\text { Menezes VA; Leal } \\
\text { RB; Pessoa RS; } \\
\text { Pontes RMES. }\end{array}$ & $\begin{array}{l}\text { Prevalência e Fatores } \\
\text { Associados à Respiração Oral } \\
\text { em Escolares Participantes do } \\
\text { Projeto Santo Amaro-Recife, } \\
2005 .\end{array}$ & Nacional & $\begin{array}{l}8-10 \\
\text { anos }\end{array}$ & $\begin{array}{l}\text { Pesquisa } \\
\text { de } \\
\text { campo }\end{array}$ & $\begin{array}{l}\text { RO } \\
\text { SE }\end{array}$ & 2006 \\
\hline XXII & $\begin{array}{l}\text { Mancini F; Yi LC; } \\
\text { Pignatari SSN; } \\
\text { Roque AC; Pisa } \\
\text { IT. }\end{array}$ & $\begin{array}{l}\text { Aplicação de Redes Neurais } \\
\text { Artificiais na Classificação de } \\
\text { Padrões Posturais em } \\
\text { Crianças Respiradoras Bucais } \\
\text { e Nasais. }\end{array}$ & Nacional & $\begin{array}{l}5-12 \\
\text { anos }\end{array}$ & $\begin{array}{l}\text { Pesquisa } \\
\text { de } \\
\text { campo }\end{array}$ & $\begin{array}{c}\text { RO/RN } \\
\mathrm{PO}\end{array}$ & 2007 \\
\hline XXIII & $\begin{array}{l}\text { Andrada e Silva } \\
\text { MA; Natalini V; } \\
\text { Ramires RR; } \\
\text { Ferreira LP. }\end{array}$ & $\begin{array}{l}\text { Análise Comparativa da } \\
\text { Mastigação de Crianças } \\
\text { Respiradoras Nasais e Orais } \\
\text { com Dentição Decídua. }\end{array}$ & Nacional & 4-5 anos & $\begin{array}{l}\text { Pesquisa } \\
\text { de } \\
\text { campo }\end{array}$ & $\begin{array}{l}\text { RO/RN } \\
\text { SE }\end{array}$ & 2007 \\
\hline XXIV & $\begin{array}{l}\text { Maciel KRA; } \\
\text { Albino RCM; Pinto } \\
\text { MMA. }\end{array}$ & $\begin{array}{l}\text { A Prevalência de Distúrbio } \\
\text { Miofuncional Orofacial nos } \\
\text { Pacientes Atendidos no } \\
\text { Ambulatório de Pediatria do } \\
\text { Hospital Luís de França. } \\
\end{array}$ & Nacional & $5-8$ anos & $\begin{array}{l}\text { Análise } \\
\text { descritiva }\end{array}$ & SE & 2007 \\
\hline XXV & $\begin{array}{l}\text { Neiva PD; } \\
\text { Kirkwood RN. }\end{array}$ & $\begin{array}{l}\text { Measurement of Neck Range } \\
\text { of Motion Among Mouth- } \\
\text { Breathing Children. }\end{array}$ & Nacional & 6-7 anos & $\begin{array}{l}\text { Pesquisa } \\
\text { de } \\
\text { campo }\end{array}$ & $\begin{array}{l}\text { RO/RN } \\
\mathrm{PO}\end{array}$ & 2007 \\
\hline XXVI & $\begin{array}{l}\text { Cattoni DM; } \\
\text { Fernandes FDM; } \\
\text { Di Francesco RC; } \\
\text { Latorre MRDO. }\end{array}$ & $\begin{array}{l}\text { Características do Sistema } \\
\text { Estomatognático de Crianças } \\
\text { Respiradoras Orais: enfoque } \\
\text { antroposcópico. }\end{array}$ & Nacional & $\begin{array}{l}7-11 \\
\text { anos }\end{array}$ & $\begin{array}{l}\text { Análise } \\
\text { descritiva }\end{array}$ & $\begin{array}{l}\text { RO } \\
\text { SE } \\
\text { PO }\end{array}$ & 2007 \\
\hline XXVII & $\begin{array}{l}\text { Menezes VA; Leal } \\
\text { RB; Moura MM } \\
\text { and Granville- } \\
\text { Garcia AF. }\end{array}$ & $\begin{array}{l}\text { Influence of Socio-Economic } \\
\text { and Demographic Factors in } \\
\text { Determining Breathing } \\
\text { Patterns: a pilot study. }\end{array}$ & Nacional & $\begin{array}{l}9-10 \\
\text { anos }\end{array}$ & $\begin{array}{l}\text { Estudo } \\
\text { piloto }\end{array}$ & RO & 2007 \\
\hline XXVIII & $\begin{array}{l}\text { Branco A; Ferrari } \\
\text { GF and Weber } \\
\text { SAT. }\end{array}$ & $\begin{array}{l}\text { Alterações Orofaciais em } \\
\text { Doenças Alérgicas de Vias } \\
\text { Aéreas. }\end{array}$ & Nacional & & & SE & 2007 \\
\hline $\mathrm{XXIX}$ & $\begin{array}{l}\text { Abreu RR; Rocha } \\
\text { RL; Lamounier JÁ; } \\
\text { Guerra ÂFM. }\end{array}$ & $\begin{array}{l}\text { Etiology, Clinical } \\
\text { Manifestations and } \\
\text { Concurrent Findings in } \\
\text { Mouth-Breathing Children. }\end{array}$ & Intern & $\begin{array}{c}3-9 \\
\text { anos }\end{array}$ & $\begin{array}{l}\text { Pesquisa } \\
\text { de } \\
\text { campo }\end{array}$ & $\begin{array}{l}\text { RO } \\
\text { SE }\end{array}$ & 2008 \\
\hline $\mathbf{X X X}$ & $\begin{array}{l}\text { Ferla A; Silva AMT } \\
\text { da; Corrêa ECR. }\end{array}$ & $\begin{array}{l}\text { Atividade Eletromiográfica } \\
\text { dos Músculos Temporal } \\
\text { Anterior e Masseter em } \\
\text { Crianças Respiradoras Orais e } \\
\text { em Respiradoras Nasais. }\end{array}$ & Nacional & $\begin{array}{l}8-12 \\
\text { anos }\end{array}$ & $\begin{array}{l}\text { Pesquisa } \\
\text { de } \\
\text { campo }\end{array}$ & $\begin{array}{l}\text { RO/RN } \\
\text { EMG }\end{array}$ & 2008 \\
\hline $\mathbf{X X X I}$ & $\begin{array}{l}\text { Yi LC; Jardim JR; } \\
\text { Inque DP; } \\
\text { Pignatari SSN. }\end{array}$ & $\begin{array}{l}\text { The Relationship Between } \\
\text { Excursion of the Diaphragm } \\
\text { and Curvatures of the Spinal } \\
\text { Column in Mouth Breathing } \\
\text { Children. }\end{array}$ & Intern & $\begin{array}{l}5-12 \\
\text { anos }\end{array}$ & $\begin{array}{l}\text { Pesquisa } \\
\text { de } \\
\text { campo }\end{array}$ & $\begin{array}{l}\text { RO } \\
\text { PO }\end{array}$ & 2008 \\
\hline XXXII & $\begin{array}{l}\text { Campanha SMA; } \\
\text { Freire LMS; } \\
\text { Fontes MJF. }\end{array}$ & $\begin{array}{l}\text { O Impacto da Asma, da Rinite } \\
\text { Alérgica e Da Respiração Oral } \\
\text { na Qualidade de Vida de } \\
\text { Crianças e Adolescentes. }\end{array}$ & Nacional & $\begin{array}{l}\text { Criança e } \\
\text { adol }\end{array}$ & $\begin{array}{l}\text { Artigo } \\
\text { revisão }\end{array}$ & RO & 2008 \\
\hline
\end{tabular}




\begin{tabular}{|c|c|c|c|c|c|c|c|}
\hline \multirow[b]{2}{*}{$\mathbf{N}^{\circ}$} & \multirow[b]{2}{*}{ Autor (es) } & \multirow[b]{2}{*}{ Título } & \multirow[b]{2}{*}{ Origem } & \multirow[b]{2}{*}{$\begin{array}{l}\text { Faixa } \\
\text { Etária }\end{array}$} & \multicolumn{2}{|c|}{ Classificação } & \multirow[b]{2}{*}{ Ano } \\
\hline & & & & & $\begin{array}{l}\text { Tipo de } \\
\text { Estudo }\end{array}$ & Temática & \\
\hline XXXIII & $\begin{array}{l}\text { Cucciaa AM; } \\
\text { Caradonna MLD. }\end{array}$ & $\begin{array}{l}\text { Oral Breathing and Head } \\
\text { Posture. }\end{array}$ & Intern & $\begin{array}{l}5-13 \\
\text { anos }\end{array}$ & $\begin{array}{l}\text { Pesquisa } \\
\text { de } \\
\text { campo }\end{array}$ & $\begin{array}{l}\text { RO } \\
\mathrm{PO}\end{array}$ & 2008 \\
\hline XXXIV & Hennig TR et al. & $\begin{array}{l}\text { Deglutição de Respiradores } \\
\text { Orais e Nasais: avaliação } \\
\text { clínica fonoaudiológica e } \\
\text { eletromiográfica. }\end{array}$ & Nacional & $\begin{array}{l}6-10 \\
\text { anos }\end{array}$ & $\begin{array}{l}\text { Pesquisa } \\
\text { de } \\
\text { campo }\end{array}$ & $\begin{array}{l}\text { RO/RN } \\
\text { SE } \\
\text { EMG }\end{array}$ & 2009 \\
\hline$X X X V$ & Motta LJ et al. & $\begin{array}{l}\text { Relação da Postura Cervical e } \\
\text { Oclusão Dentária em Crianças } \\
\text { Respiradoras Orais. }\end{array}$ & Nacional & $\begin{array}{l}6-10 \\
\text { anos }\end{array}$ & $\begin{array}{l}\text { Estudo } \\
\text { observ }\end{array}$ & $\begin{array}{l}\text { RO/RN } \\
\text { SE } \\
\text { PO }\end{array}$ & 2009 \\
\hline XXXVI & $\begin{array}{l}\text { Lemos CM; } \\
\text { Wilhelmsen NSW; } \\
\text { Mion OG; Mello } \\
\text { Junior JF. }\end{array}$ & $\begin{array}{l}\text { Alterações Funcionais do } \\
\text { Sistema Estomatognático em } \\
\text { Pacientes com Rinite } \\
\text { Alérgica: estudo caso- } \\
\text { controle. }\end{array}$ & Nacional & $\begin{array}{l}6-55 \\
\text { anos }\end{array}$ & $\begin{array}{l}\text { Estudo } \\
\text { de caso }\end{array}$ & $\begin{array}{l}\mathrm{RO} \\
\mathrm{SE}\end{array}$ & 2009 \\
\hline XXXVII & $\begin{array}{l}\text { Basso DBA; } \\
\text { Souza JA; } \\
\text { Pasinato F; } \\
\text { Corrêa ECR; Silva } \\
\text { AMT. }\end{array}$ & $\begin{array}{l}\text { Estudo da Postura Corporal } \\
\text { em Crianças com Respiração } \\
\text { Predominantemente Oral e } \\
\text { Escolares em Geral. }\end{array}$ & Nacional & $\begin{array}{l}8-13 \\
\text { anos }\end{array}$ & $\begin{array}{l}\text { Pesquisa } \\
\text { de } \\
\text { campo }\end{array}$ & $\begin{array}{l}\mathrm{RO} \\
\mathrm{PO}\end{array}$ & 2009 \\
\hline XXXVIII & $\begin{array}{l}\text { Menezes VA; } \\
\text { Tavares RLO; } \\
\text { Granville-Garcia af }\end{array}$ & $\begin{array}{l}\text { Síndrome da Respiração Oral: } \\
\text { alterações clínicas e } \\
\text { comportamentais. }\end{array}$ & Nacional & Criança & $\begin{array}{l}\text { Artigo } \\
\text { Revisão }\end{array}$ & $\begin{array}{l}\text { RO } \\
\text { SE }\end{array}$ & 2009 \\
\hline XXXIX & Felcar & $\begin{array}{l}\text { Prevalência de Respiradores } \\
\text { Bucais em Crianças de Idade } \\
\text { Escolar }\end{array}$ & Nacional & 6-9 anos & $\begin{array}{l}\text { Pesquisa } \\
\text { de } \\
\text { campo }\end{array}$ & RO & 2010 \\
\hline $\mathbf{X L}$ & $\begin{array}{l}\text { Nishimura CM; } \\
\text { Gimenez SRML }\end{array}$ & $\begin{array}{l}\text { Perfil da Fala do Respirador } \\
\text { Oral. }\end{array}$ & Nacional & Criança & $\begin{array}{l}\text { Artigo } \\
\text { revisão }\end{array}$ & $\begin{array}{c}\mathrm{RO} \\
\text { Dist Fala }\end{array}$ & 2010 \\
\hline
\end{tabular}

Legenda: $\mathrm{RO}=$ respirado oral; $\mathrm{RN}=$ respirador nasal; $\mathrm{ROF}=$ respirador oral funcional; $\mathrm{ROO}=$ respirador oral orgânico; $\mathrm{SE}=$ sistema estomatognático; PO = postura corporal; EMG = eletromiografia; Intern = Internacional; observ = observacional; adol = adolescente.

Figura 1 - Artigos publicados a partir do ano 2000 que abordam a temática da postura corporal, do sistema estomatognático e dos respiradores orais em crianças

\section{Sistema estomatognático e a respiração oral}

Na primeira infância, é comum se encontrar um padrão respiratório, ora pelo nariz, ora pela boca, conhecido como padrão misto. Para que este tipo respiratório ocorra, é necessário o vedamento labial ou outros fechamentos da cavidade oral, como o contato do dorso da língua com o palato duro ou da base da língua com o palato mole. Para isso, é importante a integridade anatômica e funcional das vias aéreas, ou seja, não deve ser apresentado impedimento à passagem do ar. Caso não haja o vedamento desses pontos ou qualquer tipo de impedimento, a respiração nasal é substituída pela oral ou predominantemente oral. Quando isso ocorre por um período maior que seis meses ${ }^{9,10}$, acarreta uma condição patológica com importantes alterações morfofuncionais no sistema estomatognático ${ }^{1,4-6}$.

A RO é muito frequente na infância e, apesar de ser um sintoma, pode ser considerada uma síndrome, denominada Síndrome de Respiração Oral, envolvendo sinais e sintomas, pois acarreta várias mudanças não só nos aparelhos envolvidos com a respiração (orofaciais), como também alterações miofuncionais que modificam o eixo corporal e sua dinâmica ${ }^{4,11-14}$.

As características físicas mais relevantes atribuídas a estes pacientes observados no estudo de Filho, Bertolini e Lopes (2006) ${ }^{15}$ são as alterações faciais como: face adenoideana, olhar triste e desatento; aumento vertical do terço inferior da face; arco maxilar estreito; palato ogival; ângulo goníaco obtuso; má oclusão dentária (mordida aberta, incisivos superiores protruídos, mordida cruzada); posição baixa do osso hióide e lábio superior curto; lábio inferior evertido; além de hipotonia dos elevadores de mandíbula, labial e lingual e incompetência; e alterações da postura de língua em repouso e nas funções ${ }^{4,7,12}$.

Falcão et al. (2003) $)^{16}$ apresentam como alterações orofaciais: face alongada e alterações das arcadas como mordida aberta anterior e cruzada. Menezes et al. (2006) ${ }^{17}$ encontraram como alterações faciais no Respirador Oral e Respirador Nasal: vedamento labial inadequado $(58,8 \% \times 5,7 \%)$, olhos caídos (40,0\% x 1,4\%), palato ogival $(38,8 \% \times$ $2,9 \%)$, mordida aberta anterior $(60,0 \% \times 30,0 \%)$, 
lábios hipotônicos $(23,8 \% \times 0,0 \%)$ e olheiras $(97,5 \%$ x $77,1 \%)$. Na pesquisa de Motonaga, Berte e Anselmo-Lima $(2000)^{18}$ as alterações morfológicas no sistema estomatognático mais comuns foram: face sugestiva de dolicocéfalo, olheiras, mandíbula abaixada, lábios entreabertos, lábios superior e inferior alterados e alterações dentárias. Bicalho, Motta e Vicente (2006) ${ }^{19}$ demonstraram prevalência em: hipotensão em lábios (55\%) e bochecha (45\%), hipertensão mentual (45\%), lábio inferior com eversão (45\%), má oclusão (70\%) e alteração de fala (65\%). Na pesquisa de Cattoni et al. (2007) os aspectos estudados mais comuns na população de $\mathrm{RO}$ também foram: posição habitual de lábios entreabertos, de língua no assoalho oral, hiperfunção do músculo mentual durante a oclusão dos lábios, lábio inferior com eversão, possibilidade de vedamento labial quando solicitada, mordida alterada e palato duro alterado, e apesar destas alterações apresentaram também simetria de bochechas.

As principais manifestações dos respiradores orais apontadas pelos autores foram: sonolência diurna, cefaléia, agitação e enurese noturna, cansaço frequente, baixo apetite, bruxismo, problemas escolares e até déficit de aprendizado e problemas comportamentais ${ }^{7,12}$. Abreu et al. $(2008)^{21}$, ao estudar crianças RO, detectaram: dormir com a boca aberta $(86 \%)$, roncar $(79 \%)$, coçar o nariz (77\%), babar no travesseiro (62\%), dificuldade respiratória noturna ou sono agitado (62\%), obstrução nasal (49\%) e irritabilidade durante o dia (43\%). Felcar et al. (2010)22, concluíram que crianças com sete anos de idade, que babavam e roncavam à noite, apresentavam maior predisposição a ocorrência da respiração oral. Menezes et al. $(2007)^{23}$ ao verificar a influência sócio-econômica e demográfica na determinação da respiração oral, obtiveram como resultado a maior prevalência de respiradores orais em escolas publicas do que em particulares.

A respiração oral pode ser de ordem orgânica (obstrutiva) ou funcional. A respiração oral orgânica deve-se a fatores obstrutivos, podendo ser causada por obstruções mecânicas no interior das cavidades nasais ou orais, nas coanas ou na rinofaringe. Os autores concordam que, dentre as alterações mais frequentes das vias aéreas superiores que podem levar a esse tipo de respiração, destacam-se: desvio do tabique ou septo nasal, hipertrofia das adenóides, malformações (congênitas) dos ossos nasais, hipertrofia dos cornetos ou de tonsilas (faríngea e/ou palatina) nasais e enfermidades pulmonares (asma, bronquite, bronquiectasia, sinusite, bronquite); infecções crônicas das amígdalas palatinas e alergias respiratórias ou doenças inflamatórias (rinite alérgica) ${ }^{3,9,11,13,24-26}$.
A respiração oral funcional ou viciosa (por hábito) não vem acompanhada de nenhuma obstrução, e se percebem como alterações mais frequentes: os vícios adquiridos, como sucção de chupeta, mamadeira e dedos; fatores psicológicos; ou também, devido à hipofuncionalidade dos músculos da face, que causa a não oclusão $|a b i a|^{27}$. Falcão et al. $(2003)^{16}$ observaram uma forte associação entre a $\mathrm{RO}$ e os hábitos bucais deletérios, como o da onicofagia.

Os resultados de Motonaga, Berte e Anselmo-Lima $(2000)^{18}$ permitiram concluir que as principais causas de respiração oral em crianças foram rinite alérgica, hipertrofia de adenóide e/ou amígdala, por hábito e patologias obstrutivas associadas. $\mathrm{Na}$ pesquisa de Abreu et al. (2008) ${ }^{20}$, os resultados mostraram como principais causas: rinite alérgica $(81,4 \%)$, hipertrofia de adenóides $(79,2 \%)$, hipertrofia de amígdalas $(12,6 \%)$ e desvio obstrutivo do septo nasal $(1,0 \%)$. No estudo de Lemos et al. $(2009)^{28}$, em que avaliaram 170 pacientes, entre 6 e 55 anos de idade, estes relatam que obstrução nasal é um sintoma predominante em quadros de rinite alérgica e está diretamente relacionada à presença de alterações funcionais do sistema estomatognático, pois os autores encontraram uma alta porcentagem de pacientes do grupo rinite com alteração do modo respiratório.

O respirador oral, em muitos casos, não pode mastigar corretamente o alimento, devido à necessidade de respirar, pois ao abrir a boca para tal, há adaptações e desequilíbrio das estruturas e funções orofaciais que comprometem a mastigação e a deglutição, e, consequentemente, gera dificuldades na alimentação. A mastigação pode ser considerada a função mais importante do sistema estomatognático, por ser a fase inicial do processo digestivo, que se inicia na boca ${ }^{3}$.

Nas funções estomatognáticas grande parte das pesquisas relata alterações, principalmente na mastigação e na deglutição. De acordo com a análise dos resultados obtidos no estudo de Lemos et al. $(2006)^{26}$, concluiu-se que há uma relação estatisticamente significante entre a respiração oral e a presença de deglutição atípica. Hennig et al. (2009) ${ }^{29}$ observaram alterações na deglutição, sendo que $87,5 \%$ dos sujeitos respiradores orais apresentaram ação labial, $75 \%$ ação mentual e $75 \%$ projeção lingual como características da deglutição adaptada, enquanto que os respiradores nasais não apresentaram tais alterações. Coelho e Terra (2004) ${ }^{24}$ concluíram que os respiradores orais apresentam alterações no padrão fisiológico de deglutição devido à alta prevalência de deglutição atípica nos portadores de má oclusão, o que mostra 
existir uma relação muito grande entre problemas ortodônticos e o padrão de deglutição.

Bicalho, Motta e Vicente (2006) ${ }^{19}$ estudaram 22 respiradores orais, sendo que $90,9 \%$ das crianças pesquisadas apresentaram alteração de deglutição $(p<0,001)$, e a participação da musculatura perioral teve prevalência $(72,7 \%)$, seguida de projeção anterior de língua $(68,2 \%)$, projeção de cabeça $(40,9 \%)$, deglutição ruidosa $(9,1 \%)$ e interposição de lábio inferior (4,5\%). Além disso, 95\% apresentaram alterações na mastigação $(p<0,001)$. Andrada e Silva et al. $(2007)^{3}$, evidenciaram que a respiração oral interfere negativamente na mastigação em relação aos aspectos: tempo mastigatório, sobras de alimento na cavidade oral, postura dos lábios e ruído durante a mastigação. Motonaga, Berte e Anselmo-Lima $(2000)^{18}$ também puderam observar alteração nos padrões normais de mastigação e deglutição nos RO. Maciel et al. $(2007)^{30}$, mostraram que $84 \%$ das crianças avaliadas apresentaram distúrbio miofuncional orofacial, sendo os mais encontrados também a mastigação e a deglutição inadequadas.

No trabalho de Ferla et al. (2008) dados dois grupos de crianças, 17 respiradoras orais $(\mathrm{RO})$ e 12 respiradoras nasais $(\mathrm{RN})$, as quais foram submetidas à avaliação eletromiográfica bilateral dos músculos temporal anterior e masseter. Nos resultados os pesquisadores puderam observar que o nível de atividade elétrica do grupo $\mathrm{RO}$ foi inferior para todos os músculos e estatisticamente significante somente para o temporal esquerdo; os respiradores orais apresentaram predomínio de atividade elétrica no lado direito e no músculo temporal durante a mastigação habitual.

Além dos problemas de respiração, mastigação, deglutição, postura e tonicidade dos órgãos fonoarticulatórios, os respiradores orais podem apresentar também distúrbio articulatório. A má-oclusão, uma das principais características do respirador oral, pode acarretar dificuldades ou desvios de produção fonético/articulatório. Entretanto, existem poucos trabalhos que relatam a ocorrência de distúrbios articulatórios decorrentes a este tipo de respiração. A fala pode ser imprecisa com presença de ceceio anterior ou lateral e a voz pode ser alterada pelo ressecamento dos tecidos da laringe que prejudica a vibração das pregas vocais ${ }^{31}$.

Grande parte dos autores pesquisados concordam que a presença da respiração oral modifica todo o sistema estomatognático, levando a alterações significantes e muitas vezes permanente. Portanto, existe uma relação intrínseca entre os componentes do sistema estomatognático e a respiração oral, o que deve ser levado em consideração nas avaliações de todos os pacientes com esssa patologia.

\section{Relação da postura corporal com as funções estomatognáticas}

O desenvolvimento neuropsicomotor normal caracteriza-se pela aquisição gradual do controle de postura com o surgimento das reações de retificação e das reações de equilíbrio. Este processo depende da integridade do Sistema Nervoso Central e evolui de forma ordenada, de tal modo que cada etapa é consequência da precedente e necessária à posterior. $\mathrm{O}$ desenvolvimento das reações de retificação e de equilíbrio permite ao indivíduo manter sua postura e equilíbrio da cabeça, tronco e extremidades inferiores em todas as circunstâncias normais, contra a ação gravitacional, enquanto braços e mãos permanecem livres para a exploração do ambiente ${ }^{32}$.

Assim, deve-se observar a atitude postural funcional adequada, visando regular a postura com conceitos neurofisiológicos modernos e analisando como estes fatores incidem no complexo orofacial. As compensações, bloqueios e fixações corporais devem ser avaliados na postura global e relacionados aos movimentos e posturas orofaciais (postura de lábios, bochecha, mandíbula, língua), pois a relação entre o sistema estomatognático e a postura de cabeça é estabelecida ao se considerar que as duas regiões possuem algumas conexões nervosas em comum. A cabeça mal posicionada em relação ao pescoço compromete a musculatura orofacial (principalmente o músculo escaleno, o esternocleidomastóideo e o platisma) e acarreta alterações na coluna no intuito de compensação. Sabe-se que a postura corporal global interfere na posição da cabeça, que por sua vez é diretamente responsável pela postura da mandíbula e da língua na cavidade oral ${ }^{33}$.

Cuccia \& Caradonna (2008) ${ }^{34}$ revisaram os artigos que relacionam o sistema estomatognático, principalmente as funções estomatognáticas, e a postura corporal. Dessa forma, confirmaram que tensões no sistema estomatognático podem contribuir para deficiências no alinhamento e no controle neural da postura, já que existem conexões entre o sistema trigeminal, as estruturas nervosas envolvidas no controle da postura e as cadeias músculo-fasciais. Em um dos artigos estudados por esses autores, os resultados indicaram que a total obstrução nasal, induz a mudança da postura da cabeça (elevação cervical).

Assim como as pesquisas realizadas, a prática clínica também verifica a relação importante que há entre a postura corporal e o sistema estomatognático. Não há como negar que durante as funções estomatognáticas, principalmente as funções vitais, ocorrem alterações importantes na postura corporal. Estas modificações ocorridas durante as 
funções se associadas a alterações já presentes na postura corporal do indivíduo, geram problemas nas funções estomatognáticas. Portanto, um indivíduo com cabeça anteriorizada consequentemente terá maior dificuldade em pelo menos algum aspecto das funções estomatognáticas e este fator é muitas vezes esquecido de ser avaliado e pesquisado, dado ao baixo número de artigos sobre o assunto.

\section{Relação da postura com as funções estomatognáticas nos respiradores orais}

Além das alterações posturais dos órgãos fonoarticulatórios, a obstrução nasal pode ser causadora ou mantenedora de cabeça mal posicionada em relação ao pescoço, com consequências para a coluna. Para compensar o peso do crânio e manter a cabeça alinhada, torna-se necessário o equilíbrio entre as forças musculares anteriores e posteriores à coluna cervical, sendo que os músculos mais fortes, na região posterior, apoiam-se na cintura escapular (cíngulo dos membros superiores). A projeção anterior da cabeça causa também mudanças na tensão da língua, face (especialmente do músculo bucinador) e nos músculos supra e infra-hioídeos, que contraem o músculo constritor da faringe, retificando o espaço oronasofaríngeo e facilitando a entrada de ar pela boca ${ }^{14,35,36}$.

A posição da cabeça e do pescoço, em relação ao tronco, tem efeito definido sobre toda a organização do corpo. Quando o pescoço está projetado anteriormente, a musculatura do pescoço e da escápula é afetada, provocando postura anormal. Os ombros rodam internamente, ficam encurvados ("ombros caídos") deprimindo assim o tórax (peito afundado), gerando a alterações no ritmo e na capacidade respiratória, pois o diafragma passa a trabaIhar numa posição mais baixa e de forma assincrônica, o que ocasiona uma respiração mais rápida e curta, criando uma deficiência de oxigenação (o volume corrente diminui associado à menor mobilidade do tórax) $)^{1,14}$.

Consequentemente, os grupos musculares tomam uma nova trajetória de função que passa a ser para frente e para baixo. Desse modo, ocorrem compensações posturais adaptativas de todo o organismo, como deformidades torácicas (principalmente aumento da cifose fisiológica), abdômen distendido (devido à flacidez muscular), antepulsão da pelve e alteração da curva lombar, os ombros rodam internamente ("ombros caídos"). A postura alterada dos ombros terá como consequência um desajuste das escápulas, que ficarão em posição de "asas abertas" ou escápulas abduzidas. Já que a localização das escápulas é determinada pelas clavículas, um desequilíbrio afetaria também os músculos ligados a elas. Como resultado destas posturas anormais, os joelhos também se adaptarão, apresentando-se em semiflexão e os pés apresentarão diminuição do arco plantar, pois com toda esta desorganização corporal, o centro de gravidade ficará mais anteriorizado e o apoio dos pés ficará mais frontal para manter o equilíbrio. Com isso, a marcha também poderá apresentar-se alterada $^{1,13,34}$.

Falcão et al. $(2003)^{17}$, avaliaram a postura corporal e quase metade da amostra apresentou cabeça anteriorizada; e a grande maioria apresentou cabeça inclinada e ombros assimétricos. Yi et al. (2008) ${ }^{37}$ afirmam que o respirador oral apresenta diminuição da lordose cervical, aumento da cifose torácica, aumento da lordose lombar e anteversão da posição da pelve. Motta et al. $(2009)^{38}$ concluiram que a anteriorização da cabeça é a alteração mais evidente em crianças respiradoras orais. Basso et al. (2009) ${ }^{39}$ apresentaram como resultados da avaliação postural: na vista anterior predominou a elevação do ombro direito, flexão de cotovelo e dedos; na vista posterior, observou-se abdução e elevação das escápulas e rotação dos joelhos; e, na vista lateral, anteriorização da cabeça, protrusão e rotação interna de ombros.

No trabalho de Lima et al. (2004) ${ }^{40}$, estes avaliaram 19 crianças RN, 26 ROF e 17 ROO, de 8 a 10 anos de idade, de ambos os sexos, por meio da biofotogrametria na face anterior, perfil e posterior. Os resultados mostraram que na angulação relativa à $2^{\underline{a}}$ vértebra torácica, local de maior proeminência torácica e 9ª torácica (T2T9), os resultados dos RN foram significantemente maiores do que os ROO. Já na angulação da 7aㅡ vértebra cervical, os resultados dos ROO foram significantemente maiores do que os ROF, e na medida relativa à T2T9, os resultados dos ROF foram significantemente maiores do que os ROO.

Os respiradores orais apresentam alterações no sistema estomatognático, que se manifestam na conformação e estrutura dos órgãos, fazendo com que o corpo saia de seu eixo. O sistema estomatognático é uma entidade fisiológica funcional, perfeitamente definida e integrada por um conjunto heterogêneo de órgãos e tecidos, cuja biologia e fisiopatologia são absolutamente interdependentes. Várias estruturas são importantes e participam do sistema estomatognático, sendo elas: dentes, mandíbula, músculos, ossos, ligamentos, vasos sanguíneos, complexo neural, ATM, sendo que estas auxiliam na realização das funções vitais (mastigação, sucção, deglutição, respiração) e sociais (fonação e articulação) de extrema sensibilidade e importância para a manutenção de todo o equilíbrio físico-biológico do ser humano. Existe uma íntima relação entre os ossos da face, dentes, 
músculos e cavidades (nasais, paranasais e orais), assim como com o sistema vascular e nervoso correspondentes. Há muito tempo é conhecida à possibilidade de ossos e dentes interferirem e provocarem alterações nas assim chamadas partes moles, sendo o inverso mais frequente, muitas vezes determinadas pelas alterações respiratórias. Ocorrem modificações contínuas em todas essas estruturas, constituindo um processo dinâmico. As alterações desse sistema provocam desequilíbrios que se manifestam na conformação dos órgãos ${ }^{1}$.

Se estas alterações não forem detectadas a tempo, poderão transformar-se em deformidades esqueléticas degenerativas, provocando graves consequências. Porém, o indivíduo não necessita ser portador de todos os sinais e sintomas que padronizam a síndrome do respirador oral para que possa ocorrer um desequilíbrio ósseo-muscular ${ }^{16}$.

Além disso, notou-se que há uma escassez de estudos que versem sobre a relação da postura corporal com o sistema estomatognático em respiradores orais. A carência é ainda maior quando se compara o grupo de respiradores orais obstrutivos com os respiradores orais funcionais, relacionando a postura corporal com o sistema estomatognático.

\section{CONCLUSÃO}

Percebe-se a partir da revisão teórica realizada que a respiração oral é tema de inúmeros artigos e textos dada a sua relevância na área da saúde. Porém, há uma carência de integralização dos estudos sobre este tema por pesquisadores de pelos profissionais de áreas distintas da saúde.

Além disso, notou-se que há uma escassez de estudos que versem sobre a relação da postura corporal com o sistema estomatognático em respiradores orais. A carência é ainda maior quando se compara o grupo de respiradores orais obstrutivos com os respiradores orais funcionais, relacionando a postura corporal com o sistema estomatognático.

\begin{abstract}
Children's body posture has been studied more and more by physical therapy, as well as mouth breather children have been studied by speech-language-hearing therapy. This study tries to check, through scientific literature, the relationship between stomatognathic functions and body posture in mouth breather children. This is a review of literature on body posture and the stomatognathic system in obstructive and functional mouth breathers. We searched, in electronic data basis such as MEDLINE, SCIELO and LILACS, and Google Scientific, articles related to these topics, published in the last 10. The selected articles were organized according to authors, title, source, age, and publishing year. When related to the type, the studies were considered: literature review articles; descriptive data analysis; field research. After selecting the texts, we identified four studies that relate posture, stomatognathic system and mouth breathing; two studies that relate stomatognathic system and posture; 13 studies relating to the stomatognathic system and mouth breathing. We may perceive that there is a lack of studies correlating body posture and stomatognathic system in oral breathers. The lack is even higher when we compare obstructive oral breathers and vicious oral breathers relating the body posture to the stomatognathic system.
\end{abstract}

KEYWORDS: Posture; Stomatognathic System; Mouth Breathing; Child

\section{REFERÊNCIAS}

1. Quintão FC, Andrade DC, Lagôa LC. A Síndrome do respirador oral, suas influências na postura e a atuação da fisioterapia. 2004. [Acesso em: 02 de Junho de 2009]. Disponível em: http://www.wgate. com.br/conteudo/medicinaesaude/fisioterapia/ respiratoria/respirador_oral.htm

2. Silva APPP, Vitalino RAB, Martinez M, Chiappetta ALML. Correlação entre postura corporal e mastigação após a dentição mista. Rev CEFAC [periódico na internet]. Out./Dez. 2004 [Acesso em: 10 de Agosto de 2010];6(4): 363-9. Disponível em: http://www.cefac.br/revista/revista64/Artigo\%204. pdf.

3. Andrada e Silva MA, Natalini V, Ramires RR, Ferreira LP. Análise comparativa da mastigação de crianças respiradoras nasais e orais com dentição decídua. Rev CEFAC, São Paulo. Abr/Jun, 2007. [Acesso em: 5 de Agosto de 2010] 9(2):190-8. 
Disponível em: http://www.scielo.br/pdf/rcefac/ v9n2/a07v9n2.pdf

4. Krakauer LH, Guilherme A. The Relantionship between Mouth Breathing and Postural Alterations in Children: A Descriptive Analysis. R Dental Press Ortodon Ortop Facial, Maringá. Set./Out. 2000. [Acesso em: 25 de Novembro de 2010] 5(5):85-92, http://www.dentalpress.com.br/artigos/pdf/161.pdf

5. Rodrigues HOSN, Faria SR, Paula FSG, Motta AR. Occurrence of mouth breathing and orofacial myology disorders in patients on orthodontic treatment. Rev CEFAC. 2005. [Acesso em: 10 de Novembro de 2010] 7(3): 356-62. Disponível em: http://www.revistacefac.com.br/revista73/ artigo\%2010.pdf

6. Ferla A, Silva AMT, Corrêa ECR. Atividade eletromiográfica dos músculos temporal anterior e masseter em crianças respiradoras orais e em respiradoras nasais. Rev Bras Otorrinolaringol 2008. [Acesso em: 15 de Outubro de 2010] 74(4):58895. Disponível em: http://www.scielo.br/pdf/rboto/ v74n4/a17v74n4.pdf

7. Menezes VA, Tavares RLO, Granville-Garcia af. Síndrome da respiração oral: alterações clínicas e comportamentais. 2009. Arquivos em Odontologia, Jul./Set. 2009; [Acesso em 05 de Novembro de 2010] 45(3):160-5. Disponível em: http://www.odonto. ufmg.br/index.php/pt/arquivos-em-odontologiaprincipal-121/edis-anteriores-principal-125/doc view/252-artigo-08?tmpl=component\&format=raw

8. Neiva PD, Kirkwood RN. Measurement of neck range of motion among mouth-breathing children. Rev. Bras. Fisioter. Set./Out. 2007; [Acesso em: 16 de Junho de 2010] 11(5): 355-60. Disponível em: http://www.scielo.br/pdf/rbfis/v11n5/en_a05v11n5. pdf

9. Barros JRC, Becker HMG, Pinto JA. Evaluation of atopy among mouth-breathing pediatric patients referred for treatment to a tertiary care Center. J Pediatr. 2006; [Acesso em: 08 de Agosto de 2010] 82:458-64. Disponível em: http://www.scielo.br/pdf/ jped/v82n6/en_v82n6a11.pdf

10. Mancini F, Yi LC, Pignatari SSN, Roque AC, Pisa IT. Aplicação de Redes Neurais Artificiais na Classificação de Padrões Posturais em Crianças Respiradoras Bucais e Nasais. Fisioterapia em Movimento. Abr./Jun. 2007. [Acesso em: 23 de Novembro de 2010] 20(2):119-26. Disponível em: http://www.seer.ufrgs.br/index.php/rita/article/view/ rita_v14_n2_p91-107/3539

11. Godoy P, Niitsuma LEM, Caromano FA. Avaliação Funcional Fisioterapêutica do Respirador Bucal. Arquivos Ciências da Saúde Unipar; 2000. [Acesso em: 25 de Novembro de 2010] 4(2):11120. Disponível em: http://revistas.unipar.br/saude/ article/view/1015/878
12. Di Francesco RC, Passerotii G, Paulucci B, Miniti A. Respiração oral na criança: repercussões diferentes de acordo com o diagnóstico. Rev Bras Otorrinolaringol. Set./out. 2004. [Acesso em: 08 de Setembro de 2010] 70(5): 665-70. Disponível em: http://www.scielo.br/pdf/\%0D/rboto/v70n5/ a14v70n5.pdf

13. Costa JR, Pereira SRA, Mitri G, Motta JC, Pignatari SSN, Weckx LLM. Relação da oclusão dentária com a postura de cabeça e coluna cervical em crianças respiradoras orais. Rev Paul Pediatria. 2005. 23(2):88-93.

14. Campanha SMA, Freire LMS, Fontes MJF. O impacto da asma, da rinite alérgica e da respiração oral na qualidade de vida de crianças e adolescentes. Rev. CEFAC. 2008. [Acesso em: 18 de Outubro de 2010] 10(4):513-9. Disponível em: http://www.scielo.br/pdf/rcefac/v10n4/v10n4a11.pdf

15. Filho DI, Bertolini MM, Lopes ML. Contribuição multidisciplinar no diagnóstico e no tratamento das obstruções da nasofaringe e da respiração bucal. R Clin Ortodon Dental Press. Dez./Jan. 2006. [Acesso em: 18 de Novembro de 2010] 4(6):90-102. Disponível em: http://www.aipro.info/drive/File/195. pdf

16. Falcão DA, Grinfeld S, Grinfeld A, Melo MVR. Oral breathers clinically diagnosed and by autodiagnosed. Body posture consequences. International Journal of Dentistry.Jul./Dez. 2003. [Acesso em: 22 de Novembro de 2010] 2(2): 250-6. Disponível em: http://www.ufpe.br/ijd/index.php/ exemplo/article/viewArticle/36

17. Menezes VA, Leal RB, Pessoa RS, Pontes RMES. Prevalência e fatores associados à respiração oral em escolares participantes do projeto Santo Amaro-Recife. 2005. Rev Bras Otorrinolaringol. 2006. [Acesso em: 10 de Novembro de 2010] 72(3): 394-9. Disponível em: http://www. scielo.br/pdf/rboto/v72n3/a17v72n3.pdf

18. Motonaga SM, Berte LC, Anselmo-Lima WT. Respiração bucal: causas e alterações no sistema estomatognático. Revista Brasileira de Otorrinolaringologia. Jul./Ag. 2000 [Acesso em: 10 de Novembro de 2010] 66(4): 373-9. Disponível em: http://www.rborl.org.br/conteudo/acervo/print_ acervo.asp? $\mathrm{id}=2482$

19. Bicalho GP, Motta AR, Vicente LCC. Evaluation of Swallowing in Mouth Breathing Children. Rev CEFAC. 2006. [Acesso em: 10 de Novembro de 2010] 8(1): 50-5. Disponível em: http://www. revistacefac.com.br/revista81/artigo05.pdf 
20. Cattoni DM, Fernandes FDM, Di Francesco RC, Latorre MRDO. Características do sistema estomatognático de crianças respiradoras orais: enfoque antroposcópico. Pró-Fono Revista de Atualização Científica. 2007 out-dez; [Acesso em: 10 de Novembro de 2010] 19(4):347-51. Disponível em: http://www.scielo.br/pdf/pfono/v19n4/ a04v19n4.pdf

21. Abreu RR, Rocha RL, Lamounier JÁ and Guerra AFM. Etiology, clinical manifestations and concurrent findings in mouth-breathing children. J. Pediatr. 2008. [Acesso em: 11 de Novembro de 2010] 84(6): 529-35. Disponível em: http://www. scielo.br/pdf/jped/v84n6/v84n6a10.pdf

22. Felcar JM, Bueno IR, Massan ACS, Torezan RP, Cardoso JR. Prevalence of mouth breathing in children from an elementary school. Ciência \& Saúde Coletiva. 2010. [Acesso em: 23 de Novembro de 2010] 15(2):437-44. Disponível em: http://www. scielo.br/pdf/csc/v15n2/v15n2a20.pdf

23. Menezes VA, Leal RB, Moura MM, GranvilleGarcia AF. Influence of socio-economic and demographic factors in determining breathing patterns: a pilot study. Rev. Bras. Otorrinolaringol. 2007. [Acesso em: 11 de Novembro de 2010] 73(6): 826-34. Disponível em: http://www.scielo.br/pdf/ rboto/v73n6/en_a14v73n6.pdf

24. Coelho MF, Terra VHTC. Implicações clínicas em pacientes respiradores bucais. Rev Patol Oral. 2004; 3(1):17-9.

25. Parra Y. El paciente respirador bucal una propuesta para el Estado Nueva Esparta 1996 2001. Acta odontol. Venez. 2004. [Acesso em: 2 de Dezembro de 2010] 42(2): 97-106. Disponível em: http://www.scielo.org.ve/scielo.php?script=sci_ arttext\&pid=S0001-63652004000200006\&Ing=en\& nrm=iso.

26. Lemos CM; Junqueira PAS; Gomez MVSG; Faria MEJ; Basso SC. Estudo da Relação entre a Oclusão Dentária e a Deglutição no Respirador Oral. SGP (Sistema de Gestão de Publicações) da RAIO; Abr./Jun. 2006. [Acesso em 2 de Dezembro de 2010] 10(2): 114-8. Disponível em: http://www. arquivosdeorl.org.br/conteudo/pdfForl/370.pdf

27. Oliveira TC. Síndrome do respirador bucal: análise fisiopatológica e uma abordagem fisioterapêutica pneumofuncional. Latu \& Sensu. Dez. 2001; 2(4):5.

28. Lemos CM, Wilhelmsen NSW, Mion OG and Mello Junior JF de. Alterações funcionais do sistema estomatognático em pacientes com rinite alérgica: estudo caso-controle. Rev. Bras. Otorrinolaringol. 2009. [Acesso em: 11 de Novembro de 2010] 75(2): 268-74. Disponível em: http://www.scielo.br/pdf/ rboto/v75n2/v75n2a18.pdf
29. Hennig TR et al. Deglutição de respiradores orais e nasais: avaliação clínica fonoaudiológica e eletromiográfica. Rev. CEFAC. 2009. [Acesso em: 12 de Setembro de 2010] 11(4):618-23. Disponível em: http://www.scielo.br/pdf/rcefac/v11n4/10.pdf

30. Maciel KRA, Albino RCM, Pinto MMA. A prevalência de distúrbio miofuncional orofacial nos pacientes atendidos no ambulatório de pediatria do Hospital Luís de França. Rev Pediatr. Jul./Dez. 2007. [Acesso em: 23 de Novembro de 2010] 8(2): 81-90. Disponível em: http://www.socep.org.br/ Rped/pdf/8.2\%20Resumo\%20Art\%200rig\%2002. pdf

31. Nishimura CM and Gimenez SRML. Perfil da fala do respirador oral. Rev. CEFAC [online]. Epub May 21, 2010. [Acesso em: 18 de Outubro de 2010] 12(3): 505-8. Disponível em: http://www.scielo.br/ $\mathrm{pdf} / \mathrm{rcefac} / \mathrm{v} 12 \mathrm{n} 3 / 36-09 . \mathrm{pdf}$

32. Val DC, Limongi SCO, Flabiano FC, Silva KCL. Stomatognathic system and body posture in children with sensoriomotor deficits. Pró-Fono R. Atual. Cient. Set./Dez. 2005. [Acesso em: 2 de Outubro de 2010] 17(3): 345-54. Disponível em: http://www. scielo.br/pdf/pfono/v17n3/v17n3a07.pdf

33. Silveira MC, Sígolo C, Quintal M, Sakano E; Tessitore A. Proposta de documentação fotográfica em motricidade oral. Rev. CEFAC. 2006. [Acesso em: 5 de Agosto de 2010] 8(4): 485-92. Disponível em: http://www.scielo.br/pdf/rcefac/v8n4/v8n4a09. pdf

34. Cucciaa AM, Caradonna MLD. Oral Breathing and Head Posture. Angle Orthodontist. 2008. 78(1):77-82.

35. Arellano JCV. Relações entre postura corporal e sistema estomatognático. JBA. Abr./Jun./ 2002; 2(6):155-64.

36. Branco A, Ferrari GF and Weber SAT. Alterações orofaciais em doenças alérgicas de vias aéreas. Rev. Paul. Pediatr. 2007. [Acesso em: 24 de Novembro de 2010] 25(3):266-70. Disponível em: http://www.scielo.br/pdf/rpp/v25n3/a12v25n3. pdf

37. Yi LC, Jardim JR, Inque DP and Pignatari SSN. The relationship between excursion of the diaphragm and curvatures of the spinal column in mouth breathing children. J. Pediatr. 2008. [Acesso em: 23 de Novembro de 2010] 84(2):171-7. Disponível em: http://www.scielo.br/pdf/jped/v84n2/ en_v84n2a14.pdf

38. Motta LJ et al. Relação da postura cervical e oclusão dentária em crianças respiradoras orais. Rev. CEFAC. 2009. [Acesso em: 08 de Novembro de 2010] 11(3): 298-304. Disponível em: http://www. scielo.br/pdf/rcefac/v11s3/a04v11s3.pdf 
39. Basso DBA, Souza JÁ, Pasinato F, Corrêa ECR, Silva AMT da. Estudo da postura corporal em crianças com respiração predominantemente oral e escolares em geral. Saúde. Santa Maria, 2009. [Acesso em: 20 de Novembro de 2010] 35(1):21-7. Disponível em: http://w3.ufsm.br/ revistasaude/2009/35(1)21-27.2009.pdf
40. Lima LCO, Baraúna MA, Sologurem MJJ, Canto RST, Gastald AC. Postural alterations in children with mouth breathing assessed by computerized biophotogrammetry. Journal of Applied Oral Science. 2004. [Acesso em: 24 de Novembro de 2010] 12(3): 232-7. Disponível em: http://www. scielo.br/pdf/jaos/v12n3/21685.pdf

Endereço para correspondência:

Patricia Girarde Machado

Rua São Paulo, 307, Ap. 302, Centro

São Leopoldo - RS - Brasil

CEP: 93010-170

E-mail: pati_girarde@ hotmail.com 